\title{
ADAPTAÇÃO DE EXTENSÃO UNIVERSITÁRIA EM ENGENHARIA DURANTE PANDEMIA - RELATO DE EXPERIÊNCIA
}

DOI: 10.37702/2175-957X.COBENGE.2021.3499

Ana Cláudia Franca Gomes - anafrancca@yahoo.com.br UFMT

Rua 13877

78068-425 - Cuiabá - MT

Ellis Karinny Furlan - efurlan44@gmail.com

UFMT

Rua Barão de Melgaço 130

78025-300 - Cuiabá - MT

Flávia Regina Pereira Santos de Siqueira - frpsantos@hotmail.com UFMT

Av. Helder Candia. 3059

78048-150 - Cuiabá - MT

Resumo: Todo saber científico deve ser construído pensando no seu impacto na sociedade; e uma das formas de se trabalhar esse pensamento crítico em alunos de engenharia é através da prática de extensão. Entretanto, a pandemia da COVID-19 trouxe diversos desafios para a academia. Um deles foi a necessidade de reestruturação dos projetos de extensão, uma vez que a Organização Mundial de Saúde recomendou o isolamento social para diminuir o contágio pelo vírus. Dessa forma, o presente artigo relatou as adaptações realizadas em ações do projeto de extensão em Educação, Geociências e Mineração, o evento intitulado MineraFérias, da Faculdade de Engenharia da Universidade Federal de Mato Grosso. As atividades realizadas na primeira edição do evento foram totalmente presenciais e incluíram uma exposição de minerais e rochas e oficinas para crianças. Na segunda edição do evento as atividades presenciais foram substituídas pela criação de um perfil no Instagram com a divulgação de conteúdo relacionado a temática central do projeto, oficinas online para crianças, live para adolescentes e disponibilização de material online na forma de um livro de colorir e uma história em quadrinhos, ambos com temas relacionados à geologia e engenharia de minas. Como resultado, foi possível manter o elo entre a instituição de ensino superior e a sociedade, através do engajamento dos graduandos em 
Engenharia de Minas e da participação da comunidade, mesmo de forma virtual durante o período de pandemia.

Palavras-chave: Educação. Aprendizagem ativa. Geociências e mineração. Ensino remoto. Ensino superior. 


\section{ADAPTAÇÃO DE EXTENSÃO UNIVERSITÁRIA EM ENGENHARIA DURANTE PANDEMIA - RELATO DE EXPERIÊNCIA}

\section{INTRODUÇÃO}

O ensino em Engenharia no Brasil é tradicionalmente atrelado à indústria, voltado para o conhecimento e inovações tecnológicas, sendo pouco direcionado para o seu papel social (KLEBA, 2017; KUHN, SIQUEIRA e GOMES, 2018).

Assim, como forma de fortalecer o papel social dos cursos de Engenharia no país, a extensão universitária surge como uma expressão do compromisso da universidade com a comunidade, permitindo que o ensino ultrapasse as barreiras da instituição, alcançando outras pessoas, que não necessariamente estão em um curso de graduação. Em adição, a extensão permite um processo contínuo de ensino e aprendizagem entre os discentes e docentes em todo o processo de planejamento, divulgação e prática do projeto elaborado (NUNES e SILVA, 2011; KLEBA 2017; KUHN, SIQUEIRA e GOMES, 2018; MARQUES, 2020.)

Segundo o Plano Nacional de Extensão, elaborado pelo Fórum de Pró-Reitores de Extensão das Universidades Públicas Brasileiras e pela Secretaria do Ensino Superior do Ministério da Educação:

"A Extensão Universitária é o processo educativo, cultural e científico que articula o Ensino e a Pesquisa de forma indissociável e viabiliza a relação transformadora entre universidade e sociedade. A Extensão é uma via de mão dupla, com trânsito assegurado à comunidade académica, que encontrará, na sociedade, a oportunidade de elaboração da práxis de um conhecimento académico".

Assim, dentre as muitas consequências positivas da prática da extensão universitária estão a superação das condições de desigualdades e exclusões regionais existentes, difusão de conhecimento, cultura de universidade voltada para questões sociais, pesquisas voltadas para a solução de problemas reais, e melhoria na qualidade de vida da população NUNES e SILVA, 2011; KLEBA 2017; KUHN, SIQUEIRA e GOMES, 2018; MARQUES, 2020.)

Mesmo com a sua importância para a comunidade, em 2020, as práticas presenciais da extensão universitária foram interrompidas no Brasil devido as orientações de isolamento da Organização Mundial da Saúde (OMS) para conter o avanço da pandemia da COVID-19.

Entretanto, a suspensão das atividades presenciais não significou, necessariamente, a quebra de vínculos já existentes entre a universidades e os públicos atendidos por elas. Abranches (2020), UFCA (2020) e Nunes et al. (2021) relataram que, de forma rápida e eficiente, muitas instituições de ensino superior responderam ao desafio da extensão de forma remota propondo e realizando canais virtuais, jornadas, seminários, e discussões de forma online.

Dessa forma, o presente artigo apresenta um relato de experiência de adaptação de extensão universitária em engenharia pré e pós pandemia, como forma de difundir ideias e inspirações para outras instituições brasileiras de ensino superior. 


\section{O PROJETO DE EXTENSÃO MINERAFÉRIAS}

No ano de 2019, o projeto de extensão "Educação, Geociências e Mineração" formado por professores e alunos do curso de Engenharia de Minas, da Faculdade de Engenharia (FAENG) da Universidade Federal de Mato Grosso (UFMT) promoveu a primeira edição do evento MineraFérias. O principal objetivo do evento foi fomentar a popularização da ciência em Mato Grosso e ressaltar a importância da mineração no diaa-dia das pessoas. Os assuntos abordados englobaram tipos de rochas, minérios, mineração e sociedade, fósseis e gemas.

O MineraFérias recebeu 78 inscrições (através do site: https://www.even3.com.br/minera2019) e ofereceu atividades gratuitas, nas dependências do campus, para crianças de 4 a 14 anos e pais ou acompanhantes nos dias 14 e 21 de dezembro 2019.

Dentre as atividades oferecidas, a primeira realizada foi a "Réplica de fósseis", uma oficina em que os discentes do curso de Engenharia de Minas fabricaram réplicas de fósseis de dinossauros, em gesso, para que as crianças atendidas pelo projeto pudessem pintá-los (com tinta guache) e aprender sobre fósseis e tempo geológico. A Figura 1 ilustra os dinossauros já pintados pelas crianças.

Figura 1: Dinossauros pintados pelas crianças na atividade "Réplica de fósseis".

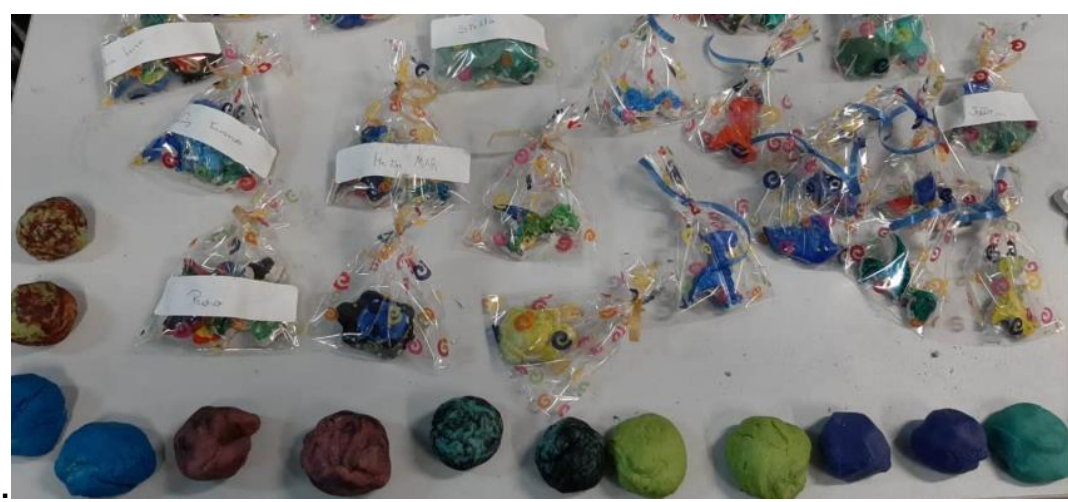

Fonte: Adaptado de Programa de extensão em geociências e mineração (2021).

A segunda atividade proposta teve o objetivo de orientar sobre a prospecção (procura) mineral. Esta atividade foi chamada de "Onde estão as pedras preciosas? Como encontramos?". Para tal, as crianças tiveram que encontrar amostras de minerais e rochas escondidas em caixas de areia, como ilustra a Figura 2. Assim, o público aprendeu um pouco sobre o trabalho do geólogo e do engenheiro de minas e também da importância da mineração. 
Figura 2: Atividade "Onde estão as pedras preciosas? Como encontramos?".

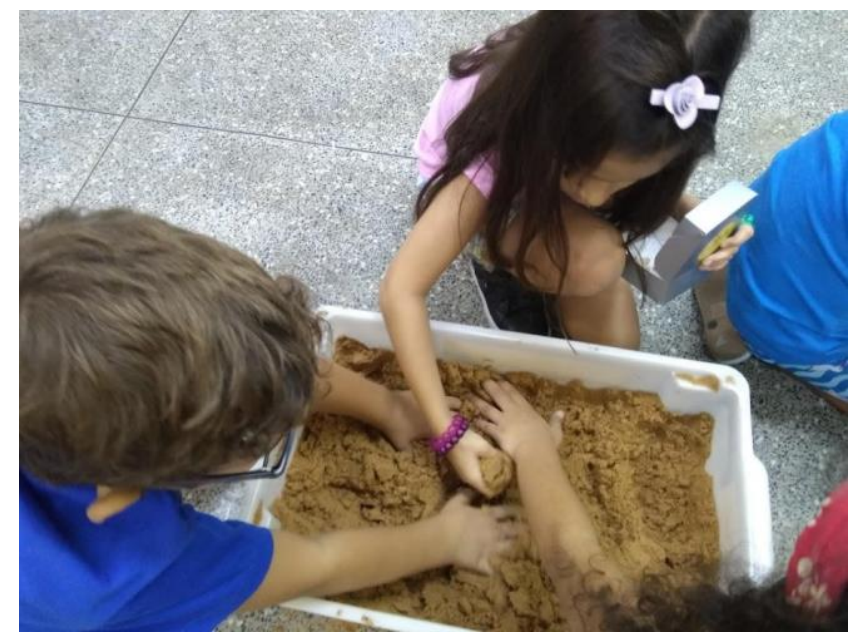

Fonte: Adaptado de Programa de extensão em geociências e mineração (2021).

A terceira atividade de nome "Minerador por um dia", mostrou como os garimpeiros da região separam o ouro e outros minerais pesados da areia. Para isso, as crianças "aprenderam a batear" com aparatos adaptados, como ilustra a Figura 3.

Figura 3:Atividade: "Minerador por um dia".

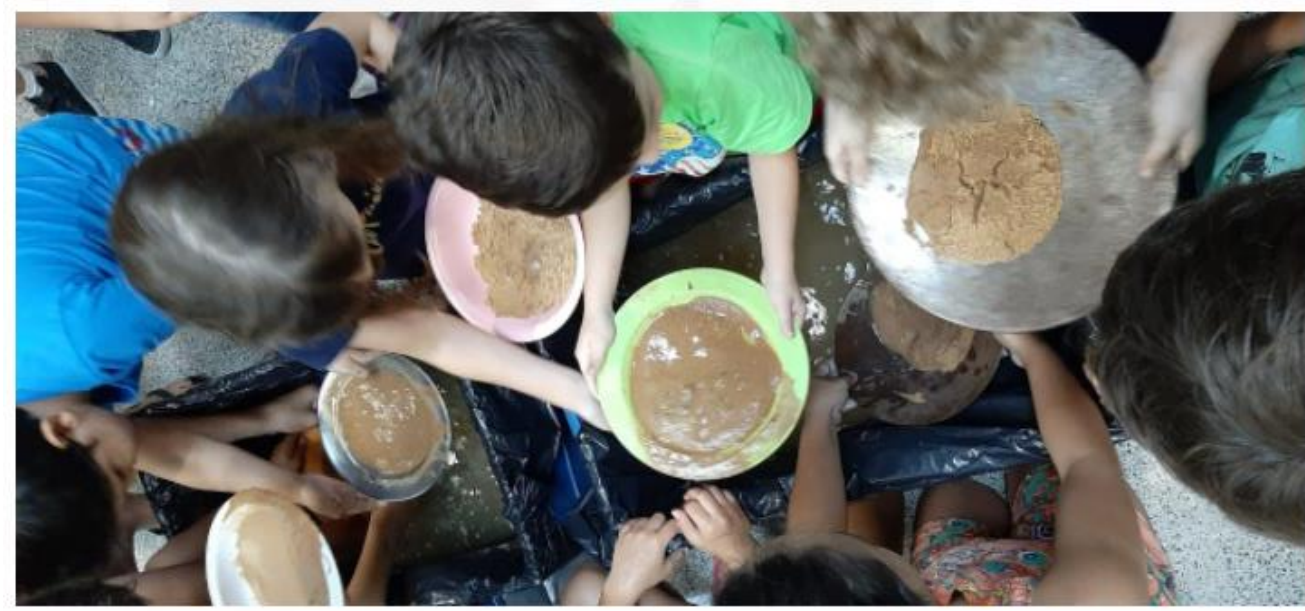

Fonte: Adaptado de Programa de extensão em geociências e mineração (2021).

Durante a realização do MineraFérias, os discentes também apresentaram minerais e rochas da litoteca do curso de graduação, uma pequena exposição de minerais, rochas e minérios de MT, como ilustra a Figura 4. Os participantes também foram presenteados com um kit de minerais comuns no estado de Mato Grosso (Figura 5) montado pela equipe do projeto. 
Figura 4: Exposição de minerais e rochas do MineraFérias.

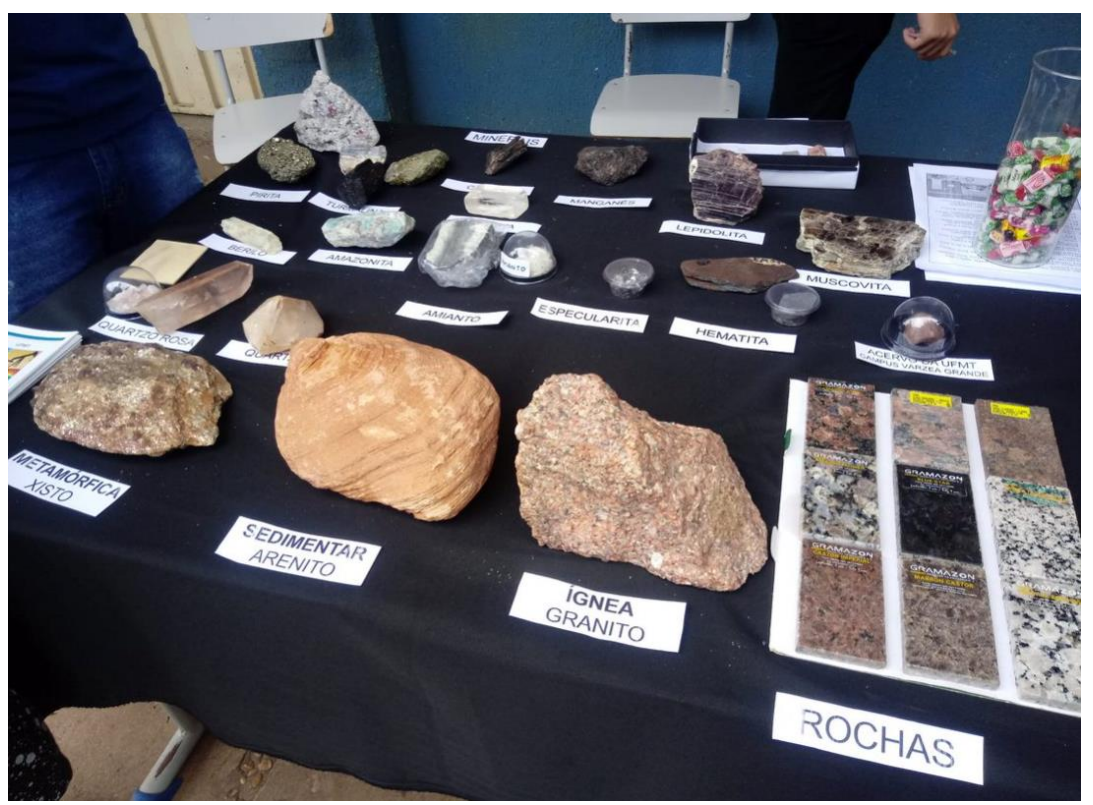

Fonte: Adaptado de Programa de extensão em geociências e mineração (2021).

Figura 5: Kit de minerais produzido para os participantes do MineraFérias.

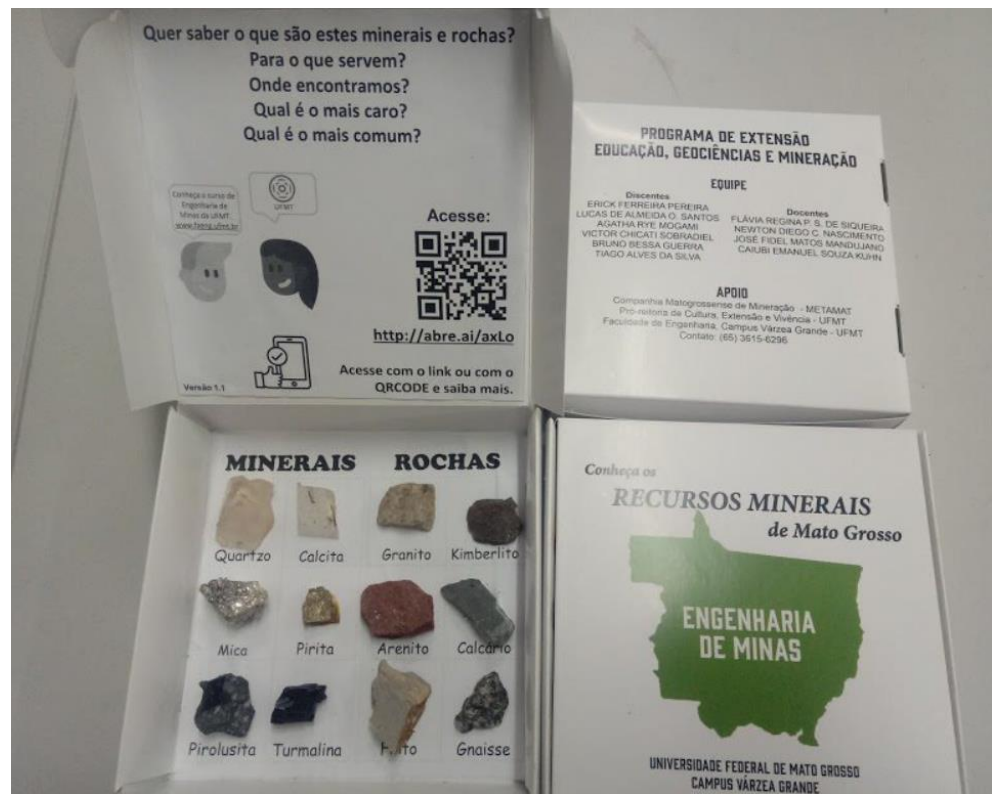

Fonte: Adaptado de Programa de extensão em geociências e mineração (2021).

O evento criado pelo projeto de extensão Educação, Geociências e Mineração foi bem avaliado pelos participantes e foi decido que seria realizada mais uma edição no ano de 2020. Entretanto, teve que ser adaptado para forma remota, em decorrência às orientações de isolamento social para conter a pandemia do COVID-19.

Assim, a segunda edição do MineraFérias foi realizada no dia 30 de janeiro de 2021, de forma online. Anteriormente a essa data, para a continuidade do elo pré-estabelecido com as crianças atendidas na primeira edição, foi criada a página no Instagram @programaextgeociencias onde são publicadas as ações da extensão universitária, e conteúdo afim de disseminar conhecimento nas áreas de geociências e mineração. 
Em dezembro de 2020, foram criados os mascotes do projeto de extensão utilizando elementos da geologia como base para as artes. Uma enquete foi divulgada na página do Instagram para a escolha do nome de cada um. Os mascotes representam minerais e rochas brasileiros e foram criados com o intuito de difundir a riqueza mineral do Brasil; e, por isso, para cada um deles, foi criado um perfil (Figura 6). Sobre os nomes ganhadores, o mascote que representa o diamante, ganhou o nome de Dito, já o carvão foi chamado de Zé Carvão, enquanto Quartzera foi o nome escolhido para o quartzo verde, e Arenaide foi o vencedor para a rocha sedimentar.

Figura 6: Mascotes do programa de Extensão Educação, Geociências e Mineração e suas respectivas descrições.

Dito
Idade: 65 milhões de anos.
Perfil: O mais preciosos e raro da turma!
Frase: "Altas pressões e temperaturas é comigo mesmo!"
Sonho: Brilhar pelo mundo!
Origem: Formação Cachoeirinha Mato Grosso.
Arenaide
Idade: 500 milhões de anos.
Perfil: Sempre tem uma surpresa escondida em suas camadas!
Frase: "Unidos somos mais fortes!"
Sonho: Contribuir para a descoberta de um novo fóssil!
Origem: Arenitos de Mato Grosso.
Quatzera
Idade: 600 milhoes de anos.
Perfil: O popular da turma!
Frase: "Quanto mais tempo para cristalizar, mais bonito fico!"
Sonho: Ser mais valorizado!
Origem: Veios de quartzo no grupo Cuiabá- Mato Grosso.
Zé Carvão
Idade: 300 milhões de anos
Perfil:É o esquentadinho e quem tem mais energia da turma!
Frase: "Sou pura energia e combustão!"
Sonho: Conhecer a floresta Amazônica!
Origem: Sul do Brasil.

Fonte: Adaptado de Programa de extensão em geociências e mineração (2021).

Decididos os nomes dos mascotes, foram abertas inscrições para o Mineraférias 2021 (através do site: https://www.even3.com.br/minera2021), e, em 30 de janeiro de 2021 as atividades realizadas de forma síncrona foram divididas em três turmas por faixa etária. Em todas elas houve a parte inicial de apresentação do projeto de extensão e apresentação dos monitores (discentes do curso de Engenharia de Minas). 
A turma 1 contou com a participação de crianças de 5 a 8 anos para as quais foram apresentadas a história do tempo geológico de forma lúdica, através de um livro de colorir, criado pela equipe do projeto, disponibilizado em formato PDF para imprimir em casa (Figura 7a). Após a apresentação dos discentes, as crianças puderam colorir o e-book com os mascotes, também previamente enviados de forma digital (Figura 7b), e compartilhar os seus desenhos (Figura 7c).

Figura 7: Mineraférias 2021: a) Divulgação da colônia de férias nas redes sociais; b) E-book dos de colorir com os mascotes do projeto; c) Criança participante do evento compartilhando sua pintura do livro de colorir.

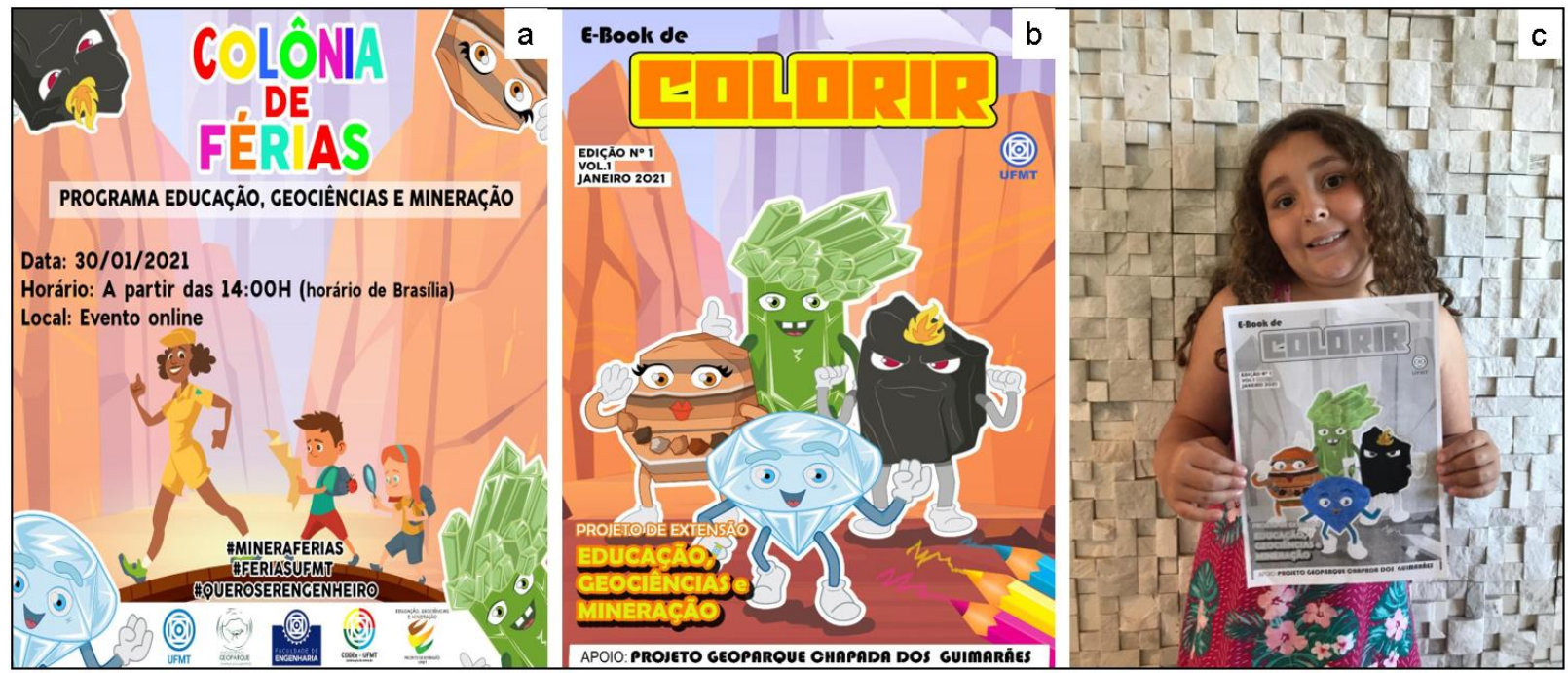

Fonte: Adaptado de Programa de extensão em geociências e mineração (2021).

A turma 2 contou com a participação de crianças entre 9 e 13 anos que assistiram o filme da Disney Moana com a explicação dos monitores sobre a formação de vulcões e tectonismo no mundo. Após, foi feita a leitura do e-book "As aventuras da turma do Mineraférias" com os mascotes do projeto (também disponibilizado em formato pdf), como mostra a Figura 8. Toda a arte dos materiais aqui ilustrados foi criada pelo discente Jefferson Emerick e as histórias foram criadas pela professora Flávia Regina Pereira Santos de Siqueira. 
Figura 8: E-book com "As aventuras da turma do Mineraférias" no formato de História em Quadrinhos com temas relacionados à geologia e mineração.
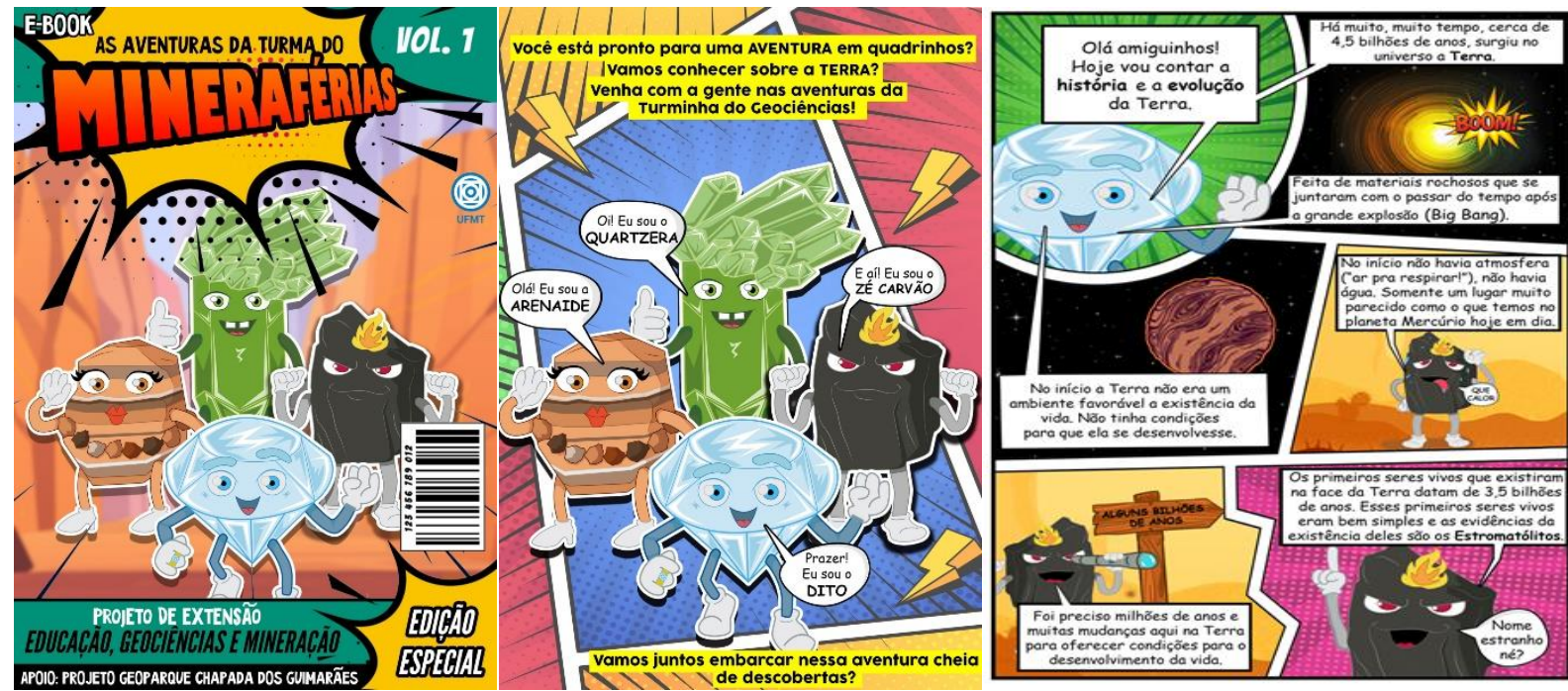

Fonte: Adaptado de Programa de extensão em geociências e mineração (2021).

Na sequência, foi realizado um jogo on-line gratuito chamado "Gartic" (disponível em: https://gartic.com.br/) no qual cada participante desenha um certo objeto e os outros jogadores devem descobrir o que é, no caso os nomes criados para o jogo foram todos a relacionados com geologia e mineração.

Por último, a turma 3 atendeu adolescentes a partir de 14 anos. O foco para essa faixa etária foi o diálogo sobre as profissões nas áreas de geografia, geologia e engenharia de minas, visando a realização do Exame Nacional do Ensino Médio (ENEM). Para tal, foi realizada a Live "Guia das profissões da geociências e mineração" (disponível em: https://www.youtube.com/watch?v=YCw5H4sG6ks) conduzida por dois alunos da UFMT e uma ex-aluna, de cada um destes cursos, contextualizando as suas experiências na graduação e mercado de trabalho (Figura 9).

Figura 9: Divulgação da Live "Guia das profissões da geociências e mineração".

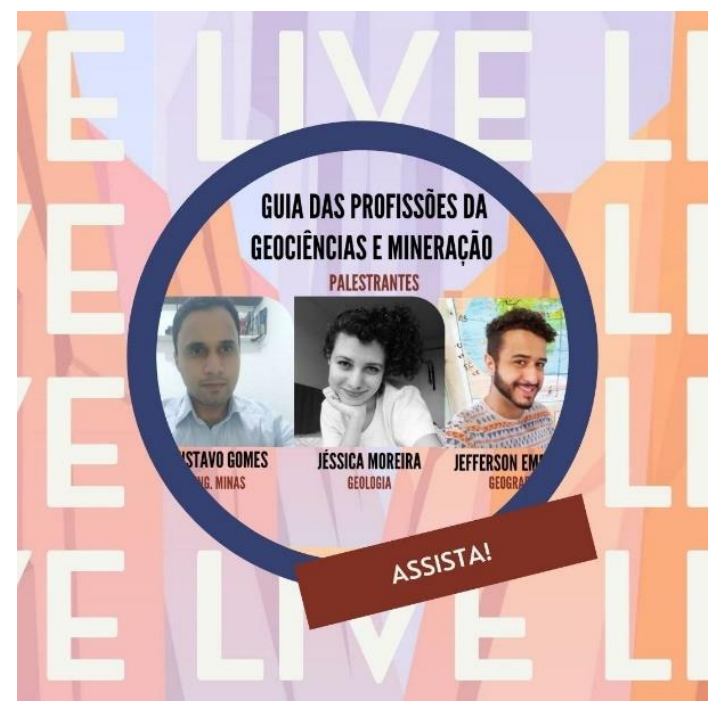

Fonte: Adaptado de Programa de extensão em geociências e mineração (2021). 
O total de participantes nas duas edições do evento foram 78 no evento de 2019 e 150 participantes no evento de 2021, além dos acessos aos e-book que somam 201 downloads. A edição Mineraférias online de 2021, da mesma forma que o MineraFérias presencial de 2019, cumpriu o objetivo de levar o conhecimento em geociências e mineração para a comunidade externa a UFMT. Entretanto, para que isso fosse possível, foi necessária uma adaptação das atividades propostas. Enquanto os eventos presenciais contaram com uma maior dinâmica e interação entre as crianças; o evento online forneceu materiais lúdicos e didáticos (e-books) e a gravação de uma live que podem ser utilizados pelo público a qualquer momento (disponível na rede social Youtube). Através dos feedbacks obtidos e pela percepção dos monitores envolvidos, outras estratégias serão estabelecidas para maior amplitude nas próximas edições do evento para a melhoria do projeto de extensão em engenharia.

\section{CONSIDERAÇÕES FINAIS}

Ações como as desenvolvidas pelos projetos do Programa de Extensão Educação, Geociências e Mineração contribuem para a difusão do conhecimento em engenharia, mesmo de forma remota.

Para que os projetos de extensão universitária continuem prestando serviços à comunidade em tempos de pandemia, faz-se necessária uma adaptação das atividades anteriormente realizadas, uma vez que o distanciamento social é indicado pela OMS.

O relato de experiência demonstrou que atividades síncronas online, como live, oficinas e trabalho lúdico conseguiram manter o elo entre a universidade e a comunidade estabelecidos com as atividades da extensão durante a pandemia. Além disso, evento em 2021, quando comparado à primeira edição do evento em 2019 que foi totalmente presencial, permitiu alcançar um público maior e mais diversificado, por causa das atividades e materiais disponíveis on-line.

\section{Agradecimentos}

Os autores agradecem à coordenação de extensão (CODEX) da UFMT.

\section{REFERÊNCIAS}

ABRANCHES, M. Extensão Universitária remota? Os desafios em tempo de pandemia. Pensar a Educação em pauta (Um jornal para a Educação Brasileira), 10 de julho de 2020. Disponível em: https://pensaraeducacao.com.br/pensaraeducacaoempauta/extensaouniversitaria-remota-os-desafios-em-tempos-de-pandemia/. Acesso em 29 de abril de 2021.

CONSELHO NACIONAL DE SAÚDE. Recomendação n 027, de 22 de abril de 2020. Disponível em: <http://conselho.saude.gov.br/recomendacoes-cns/1132-recomendacao-n027-de-22-de-abril-de-2020 >. Acesso em: 20 abr. 2021.

KLEBA, J. B. Engenharia engajada - desafios de ensino e extensão. Revista Tecnologia e Sociedade, v. 13, n.27, p. $170-187,2017$.

KUHN, C. E. S; SIQUEIRA, F. R. R. S.; GOMES, A. C. F. Extensão universitária e desenvolvimento do pensamento crítico de estudantes de engenharia de minas e geologia. Research, Society and Development, v. 8, n. 3, 2018. https://doi.org/10.33448/rsd-v8i3.730.

NUNES, A. L. P. F.; SILVA, M. B. C. A estensão universitária no ensino superior e a 
sociedade. Mal Estar e Sociedade, n. 7, p. 119 - 133, 2011.

NUNES, R. K. S.; MACIEL, G. A. S.; ALMEIDA, E. B.; GUEDES, M. R.; HENN, R. Desafios e adaptações da extensão universitária em tempos de pandemia: relato de experiência. Revista Ciência Plural, v. 7, n. 1, p. 211-223, 2021. https://doi.org/10.21680/24467286.2021v7n1ID23003

PLANO NACIONAL DE EXTENSÃO UNIVERSITÁRIA. Disponível em: < https://www.ufmg.br/proex/renex/images/documentos/Plano-nacional-de-extensaouniversitaria-editado.pdf>. Acesso em 29 de abril de 2021.

PROGRAMA DE EXTENSÃO EM GEOCIÊNCIAS E MINERAÇÃO. Disponível em: <https://www.instagram.com/programaextgeociencias/>. Acesso em 29 de abril de 2021.

PROGRAMA DE EXTENSÃO EM GEOCIÊNCIAS E MINERAÇÃO. Disponível em: https://www.youtube.com/channel/UCRIRRC8JRVL2PKVAWCZUXeg/videos. Acesso em 02 de abril de 2020.

UFCA. A extensão em tempo de pandemia: atuação das ações durante o isolamento social. Disponível em: <https://www.ufca.edu.br/noticias/a-extensao-em-tempo-de-pandemiaatuacao-das-acoes-durante-o-isolamento-social/>. Acesso em 29 de abril de 2021.

\title{
ADAPTATION OF A UNIVERSITY EXTENSION PROGRAM IN ENGINEERING DURING PANDEMIC TIMES - EXPERIENCE REPORT
}

\begin{abstract}
All scientific knowledge must be constructed based on its impact on society; and one of the ways to work this critical- thinking on engineering students is through extension practice. However, the COVID-19 pandemic brought several challenges to the academy. One of them was the need to restructure extension projects, since the World Health Organization recommended social isolation to reduce contagion by the virus. Thus, this article reported the adaptations made in the extension project in Education, Geosciences and Mining, entitled MineraFérias, from the Faculty of Engineering of the Federal University of Mato Grosso. Activities were replaced by the creation of an Instagram profile with the dissemination of content related to the central theme of the project, availability of online material and synchronous activities with children and teenagers. As a result, it was possible to maintain the link between the higher education institution and society, through the engagement of undergraduate Mining Engineering students and the participation of the community, even in a virtual way.
\end{abstract}

Keywords: Education. Active learning. Geosciences and mining. Online learning. 